\title{
Research on Judgment Aggregation Based on Logic
}

\author{
Dai $\mathrm{Li}^{1}$, Zhang Jihua ${ }^{2}$ \\ ${ }^{1}$ School of Literature and Chinese for Foreigners, Mianyang Normal University, 621006 Mianyang \\ Sichuan, China \\ ${ }^{2}$ Department of Science and Technology, Mianyang Normal University, 621006 Mianyang Sichuan, \\ China
}

\begin{abstract}
Preference aggregation and judgment aggregation are two basic research models of group decision making. And preference aggregation has been deeply studied in social choice theory. However, researches of social choice theory gradually focus on judgment aggregation which appears recently. Judgment aggregation focuses on how to aggregate many consistent logical formulas into one, from the perspective of logic. We try to start with judgment aggregation model based on logic and then explore different solutions to problem of judgment aggregation.
\end{abstract}

Keywords. rationality; preference aggregation; judgment aggregation; problem of judgment aggregation; solutions

\section{Introduction}

After American famous economist Professor Kenneth Arrow published his classic work Social Choice and Individual Values, researches begin to focus more and more on social choice theory. Social choice theory mainly considers about how can a group aggregate its members' preference and then make a decision. There are many examples, for instance, selecting candidates in a party or committee, solving air pollution or noise pollution all need group decision making. Researches on social choice theory have great theoretical significance and real application value in promoting the scientification and democratization of political and economic decision making.

Preference aggregation has been deeply studied in social choice theory. It mainly cares about whether we can build a process moving from the known individual preference to social decision making mode, at the same time; make the process fit certain reasonable conditions. The necessity of this part can be well explained in following "Condorcet Paradox". As it shows in Table 1:

Table 1. The Condorcet Paradox (P.S: (b, a) means that a is better than $b$ )

\begin{tabular}{|l|l|l|l|}
\hline & $\{\mathrm{a}, \mathrm{b}\}$ & $\{\mathrm{b}, \mathrm{c}\}$ & $\{\mathrm{a}, \mathrm{c}\}$ \\
\hline Member 1 & $(\mathrm{~b}, \mathrm{a})$ & $(\mathrm{c}, \mathrm{b})$ & $(\mathrm{c}, \mathrm{a})$ \\
\hline Member 2 & $(\mathrm{a}, \mathrm{b})$ & $(\mathrm{c}, \mathrm{b})$ & $(\mathrm{a}, \mathrm{c})$ \\
\hline Member 3 & $(\mathrm{b}, \mathrm{a})$ & $(\mathrm{b}, \mathrm{c})$ & $(\mathrm{a}, \mathrm{c})$ \\
\hline The Group & $(\mathrm{b}, \mathrm{a})$ & $(\mathrm{c}, \mathrm{b})$ & $(\mathrm{a}, \mathrm{c})$ \\
\hline
\end{tabular}

This is an Open Access article distributed under the terms of the Creative Commons Attribution License 4.0, which permits unrestricted use, distribution, and reproduction in any medium, provided the original work is properly cited. 
Suppose that there is a group which consists of three voters. The group should sort three alternatives according to preference. At the same time, assume preference of the group is reasonable which means its preference is transitive (as for three random alternatives $a, b, c$, if a is better than $b$ and at the same time, $\mathrm{b}$ is better than c, thus, a is superior to c), and complete (as for two random alternatives $a, b$, either $a$ is better than $b$ or $b$ is better than $a)$. The group's preference mode can be reached by majority vote aggregation which means that if the majority in the group holds the view that the first alternative is superior to the second, thus the group holds the same view with the majority. We take $a, b, c$ as three alternatives and take 1, 2, and 3 as three voters. Assume that voter 1 thinks a is better than $\mathrm{b}, \mathrm{b}$ is better than $\mathrm{c}$ and $\mathrm{a}$ is better than $\mathrm{c}$; voter 2 holds the view that $\mathrm{b}$ is better than $\mathrm{c}, \mathrm{c}$ is better than $\mathrm{a}$, and $\mathrm{b}$ is better than $\mathrm{a}$; while voter 3 agrees that $\mathrm{c}$ is better than $\mathrm{a}$, $\mathrm{a}$ is better than $\mathrm{b}$, and $\mathrm{c}$ is better than $b$. Thus, the majority agrees a is better than $b, b$ is better than $c$, and $c$ is better than $a$. We can find that individuals' preference is rational, but the result of majority vote aggregation is irrational, for group preference which is aggregated by those of individuals' is not transitive. "The Condorcet Paradox" shows that majority vote aggregation isn't fit those known rational conditions. Can we figure out other methods to aggregate individual preference and make them rational? ${ }^{[1]}$ Arrow Impossibility Theorem says no.

Actually, there are many problems in group decision making and the problem of preference aggregation is one of them. "Discursive Dilemma" shows that judgment aggregation also has similar problem. ${ }^{[2]}$ As it shows in Table 2:

Table 2. The Discursive Dilemma

\begin{tabular}{|c|c|c|c|}
\hline & $\mathrm{p}$ & $\mathrm{p} \rightarrow \mathrm{q}$ & $\mathrm{q}$ \\
\hline Expert 1 & $\mathrm{N}$ & $\mathrm{Y}$ & $\mathrm{N}$ \\
\hline Expert 2 & $\mathrm{Y}$ & $\mathrm{N}$ & $\mathrm{N}$ \\
\hline Expert 3 & $\mathrm{Y}$ & $\mathrm{Y}$ & $\mathrm{Y}$ \\
\hline The Group & $\mathrm{Y}$ & $\mathrm{Y}$ & $\mathrm{N}$ \\
\hline
\end{tabular}

A discussion group which is composed of three experts should make a group judgment on the following logically related propositions. (Agree or Oppose)

p: Emission load of carbon dioxide exceeds certain limit value $\mathrm{x}$.

$\mathrm{p} \rightarrow \mathrm{q}$ : If emission load of carbon dioxide exceeds certain limit value $\mathrm{x}$, the global will get warm.

q: The global will get warm.

The first expert agrees $\mathrm{p} \rightarrow \mathrm{q}$, and opposes $\mathrm{p}$ as well as $\mathrm{q}$. The second expert agrees $\mathrm{p}$, and opposes $\mathrm{p} \rightarrow \mathrm{q}$ as well as $\mathrm{q}$. The third expert agrees three propositions. From the perspective of individual, the judgment of these experts is rational which means individual judgment is logically consistent here. If we figure out the group judgment by majority vote aggregation, the group should agree $\mathrm{p}$ as well as $\mathrm{p} \rightarrow \mathrm{q}$ and oppose $\mathrm{q}$. It is clear that the group judgment is irrational when we adopt majority vote aggregation to aggregate individuals' preference, for the group's judgment isn't logically consistent.

\section{Preference aggregation and judgment aggregation}

Preference aggregation focuses on aggregating preference of several individuals which are in an alternative to a social welfare function which can represent the preference of the group. Judgment aggregation cares about judgment aggregation rules of aggregation logic formulas.

${ }^{[1]}$ Kenneth J. Arrow. Individual Values and Social Choice. New York: Wiley, 1951; 2d ed., 1963.

${ }^{[2]}$ Dietrich F., and List, C. (2007). Arrow's theorem in judgment aggregation. Social Choice and Welfare, 29(1): 19-33. 


\subsection{Preference aggregation}

A social welfare function refers to a process or rule which we can put in individuals' preference relation (a preference relation means a specific binary relation in alternative collection) and work out a preference relation which can represent the group's. We assume all the preference relations which are discussed in the following part are strict preference relations.

In form, taking $\mathrm{K}=\{\mathrm{a}, \mathrm{b}, \mathrm{c} \ldots\}$ as an alternative collection (usually we assume that there are at least two alternatives), $\mathrm{N}=\{1,2 \ldots \mathrm{n}\}$ is a subject collection (usually we assume that there are at least two subjects). A preference relation $\mathrm{R}$ on $\mathrm{K}$ is a strict linear sequence, that is a antisymmetrical (To any two alternatives $a$ and $b$, if $a R b, b R a$ is false), transitive (To any three alternatives $a, b, c$, if $a R b$ and $b R c$, thus aRc), and complete (To any two alternatives $a$ and $b$, there is either $a R b$ or bRa) binary relation. Ri represents a preference relation of subject $\mathrm{i}$ on $\mathrm{K}$, while $\mathrm{L}(\mathrm{K})$ represents collection of all preference relations on $K$. A preference collection is a $n$-tuple $(R 1, R 2 \ldots R n) \in L(K) n$, and $R i(1 \leq i \leq n)$ represents a preference relation of subject $i$. Thus, a social welfare function is $F: L(K) n \rightarrow L(K)$.

Generally, a social welfare function $\mathrm{F}$ should meet these following rational conditions:

(1). Independence of Irrelevant Alternatives

The preference order of two alternatives for a group only depends on individuals' preference ordering, and has nothing to do with other factors. It can be showed as:

$\forall(\mathrm{R} 1, \ldots, \mathrm{Rn}) \in \mathrm{L}(\mathrm{K}) \mathrm{n} \forall(\mathrm{S} 1, \ldots \mathrm{Sn}) \in \mathrm{L}(\mathrm{K}) \mathrm{n} \forall \mathrm{a} \in \mathrm{K} \forall \mathrm{b} \in \mathrm{K}(\forall \mathrm{i} \in \mathrm{N}(\mathrm{aRib} \Leftrightarrow \mathrm{aSib}) \Rightarrow(\mathrm{aF}(\mathrm{R} 1, . ., \mathrm{Rn}) \mathrm{b} \Leftrightarrow \mathrm{aF}($ $\mathrm{S} 1, \ldots \mathrm{Sn}) \mathrm{b}))$;

(2). Pareto Optimality Principle

If all individuals agree an alternative is better than the other, thus, the group will holds the same view. It can be showed as:

$\forall(\mathrm{R} 1, \ldots, \mathrm{Rn}) \in \mathrm{L}(\mathrm{K}) \mathrm{n} \forall \mathrm{a} \in \mathrm{K} \forall \mathrm{b} \in \mathrm{K}(\forall \mathrm{i} \in \mathrm{N}$ aRib $\Rightarrow \mathrm{aF}(\mathrm{R} 1, \ldots, \mathrm{Rn}) \mathrm{b}) ;$

(3). Non-dictatorship

We should avoid ignoring other individuals' different preference and making certain fixed subject's preference always be the group's preference. It can be showed as:

$\neg \exists \mathrm{i} \in \mathrm{N} \forall(\mathrm{R} 1, \ldots, \mathrm{Rn}) \in \mathrm{L}(\mathrm{K}) \mathrm{n} \mathrm{F}(\mathrm{R} 1, \ldots, \mathrm{Rn})=\mathrm{Ri}$

These conditions seems so natural and rational that people always treat them as conditions which social welfare functions must meet. However, Professor Arrow has proved in his book Social Choice and Individual Values: if there are at least three alternatives, there is no social welfare function which can meet independence of irrelevant alternatives, Pareto optimality principle and non-dictatorship at the same time. This is famous "Arrow Impossibility Theorem", or "Arrow's Theorem" for short. ${ }^{[3]}$ Arrow's Theorem is a milestone of social choice theory; it shows the impossibility to aggregate individuals' rational preference to the group's rational one.

\subsection{Judgment aggregation}

Judgment aggregation researches on aggregation from the perspective of logic. It focuses on when every subject is given a logic formulas set which represents the consistency of their judgment or belief, how can we aggregate these logic formulas sets into one which represent the consistency of the group's judgment or belief through so call rules of judgment aggregation.

In form, taking $\mathrm{N}=\{1,2 \ldots \mathrm{n}\}$ as a subjects set which has $\mathrm{n}$ subjects (usually at least two), $\mathrm{L}$ is a basic logic of judgment aggregation which we discuss. Its language $\mathcal{L}$ (L) includes $\neg$ and $\rightarrow$ which represent connectives with logical semantics. The agenda based on $\mathrm{L}$ is a nonempty set $\mathrm{A} \subseteq \mathcal{L}(\mathrm{L})$, for any formula $\Phi$ which doesn't begin with $\neg, \Phi \in \mathrm{A}$ and if and only if $\neg \Phi \in \mathrm{A}$, we assume the double negation can cancel out, that is $\neg \neg \Phi$ is $\Phi$. We usually call an element in A as an agenda item. For any subset $\mathrm{A}^{\prime}$ of $\mathrm{A}$, if there is no $\Phi \in \mathcal{L}(\mathrm{L})$ to make $\mathrm{A}^{\prime} \vdash \mathrm{L} \Phi \wedge \neg \Phi$, thus $\mathrm{A}^{\prime}$ is consistent. For every formula

${ }^{[3]}$ Kenneth J. Arrow, Individual Values and Social Choice. New York: Wiley, 1951; 2d ed., 1963. 
$\Phi \in \mathrm{A}$ which does not start with $\neg$, there is $\Phi \in \mathrm{A}^{\prime}$ or $\neg \Phi \in \mathrm{A}^{\prime}$, thus $\mathrm{A}^{\prime}$ is complete. The individual judgment set of subject $\mathrm{i}$ which we call $\mathrm{Ai}$ is a complete and consistent subset of agenda $\mathrm{A}, \mathrm{p} \in \mathrm{Ai}$ represents that $i$ agrees with agenda item $p$, that is, subject $i$ thinks $p$ is true. A judgment combination is a n-tuple combination $(A 1, A 2, \ldots, A n)$, and $A i(1 \leq i \leq n)$ is the individual judgment set of $i(1 \leq i \leq n)$. $J$ $(\mathrm{A}, \mathrm{L})$ represents a set of all individuals' or the group's judgment set on agenda A, while $J(A, L) n$ represents the set of all judgment combinations on agenda $A$. if $\gamma \in J(A, L) n$, we take $\gamma \mathrm{i}(1 \leq \mathrm{i} \leq \mathrm{n})$ as the i-st $(\gamma=(\gamma 1, \ldots, \gamma 3))$ element in $\gamma$, that is the individual judgment set of subject $\mathrm{i}$ in judgment combination $\gamma$. Thus, the function of the rule of judgment aggregation is $f: J(A, L) n \rightarrow J(A, L)$.

The rule for judgment aggregation should meet following rational conditions:

(1). Independence

The group's judgment on any agenda item in an agenda only depends on individuals' judgment on this agenda item and has nothing to do with other factors. It can be showed as:

$\forall \mathrm{p} \in \mathrm{A} \forall(\mathrm{A} 1, \ldots, \mathrm{An}) \in \mathrm{J}(\mathrm{A}, \mathrm{L}) \mathrm{n} \forall(\mathrm{B} 1, \ldots, \mathrm{Bn}) \in \mathrm{J}(\mathrm{A}, \mathrm{L}) \mathrm{n}(\forall \mathrm{i} \in \mathrm{N}(\mathrm{p} \in \mathrm{Ai} \Leftrightarrow \mathrm{p} \in \mathrm{Bi}) \Rightarrow(\mathrm{p} \in \mathrm{f}(\mathrm{A} 1, \ldots, \mathrm{An}) \Leftrightarrow \mathrm{p}$ $\in \mathrm{f}(\mathrm{B} 1, \ldots, \mathrm{Bn})))$

(2). Unanimity

If all individuals agree with certain agenda item in the agenda, then the group holds the same view. It can be showed as:

$\forall \mathrm{p} \in \mathrm{A} \forall(\mathrm{A} 1, \ldots, \mathrm{An}) \in \mathrm{J}(\mathrm{A}, \mathrm{L}) \mathrm{n}(\forall \mathrm{i} \in \mathrm{N} \mathrm{p} \in \mathrm{Ai} \Rightarrow \mathrm{p} \in \mathrm{f}(\mathrm{A} 1, \ldots, \mathrm{An}))$

(3). Non-dictatorship

We should not ignore others' different judgment and make a fixed individual's judgment always be the group's. It can be showed as:

$\neg \exists \mathrm{i} \in \mathrm{N} \forall(\mathrm{A} 1, \ldots, \mathrm{An}) \in \mathrm{J}(\mathrm{A}, \mathrm{L}) \mathrm{n} \mathrm{f}(\mathrm{A} 1, \ldots, \mathrm{An})=\mathrm{Ai}$

Discursive Dilemma: if there are at least three subjects need to make a judgment on at least two different formulas $\mathrm{p}$ and $\mathrm{q}$, and their material contain formula $\mathrm{p} \rightarrow \mathrm{q}$, and then we may find out an inconsistent group judgment if we adopt majority vote aggregation.

Similar to Arrow's Theorem and many other impossibility theorems, there are also several impossibility theorems in judgment aggregation. For both judgment aggregation and preference aggregation face the similar problems, researches gradually focus on judgment aggregation. Advantages of judgment aggregation which preference aggregation does not have provide us with new interest. Judgment aggregation explicitly shows the close connect between logic and social choice theory and at the same time raises social choice theory to a higher abstract level, a broader and more natural one. Judgment aggregation mode based on logic explores a new road for researches on social choice theory and also provides new ideas to solve problems in social choice theory.

\section{Solution to problems of judgment aggregation}

These impossibility theorems in judgment aggregation not only prove that there is no perfect rule for aggregation, but also make us realize that we should relax these conditions to figure out an aggregation rule which can be accepted. For those conditions which rules of judgment aggregation should meet we mention before, we can restrict the domain of aggregation rule, relax restrictions to output or weaken these conditions for independence instead to get rid of impossibility in judgment aggregation. (We do not consider uniformity, non-dictatorship and other approaches which people are not satisfied here.)

\subsection{Restriction to domain}

The impossibility theorems of judgment aggregation restrain rule of judgment aggregation in domain of all judgment combinations which consist of any consistent and complete individual judgment sets. Thus there is no restriction to tolerable differences between individuals. However, to increase consistency and cohesive force between individuals, it is rational to restrict individuals' judgment to a 
smaller range. Based on List and many other people's achievements, Dietrich and List propose that whether there is rational restriction of domain to make sure that majority judgment of agenda items is consistent. Some restrictions, which are discussed, are similar to some classical that in preference aggregation (such as uni-modal restriction) in essence. And one-dimensional linear arrangement is a restriction to domain of rules of judgment aggregation. For a given judgment combination, if all individuals in the group can arrange agenda items from left to right which can make sure that all individuals who agree with proposition $\mathrm{p}$ are on left side or right side of all individuals who oppose $\mathrm{p}$. Then this judgment combination can be one-dimensional linear arranged. For instance, taking the experts discussion group as example, the agenda includes following proposition and their negation:

p: Emission load of carbon dioxide exceeds certain limit value $x$.

$\mathrm{p} \rightarrow \mathrm{q}$ : If emission load of carbon dioxide exceeds certain limit value $\mathrm{x}$, the global will get warm.

q: The global will get warm.

As it shows in Table 3: individuals 1, 2, 3 which are on left side of experts discussion group agree with $\mathrm{p}$, while individuals 4, 5 which are on right side oppose p; individuals $3,4,5$ which are on right side agree with $\mathrm{p} \rightarrow \mathrm{q}$, and individuals 1,2 on left side oppose $\mathrm{p} \rightarrow \mathrm{q}$; while individuals 4 , 5 on right side agree with q, and individuals 1, 2, 3 on left side oppose q. Thus this result is a judgment combination which can be one-dimensional linear arranged.

Table 3. Y represents "Agree" and N represents "Oppose"

\begin{tabular}{|c|c|c|c|c|c|}
\hline & 1 & 2 & 3 & 4 & 5 \\
\hline$p$ & $\mathrm{Y}$ & $\mathrm{Y}$ & $\mathrm{N}$ & $\mathrm{N}$ & $\mathrm{N}$ \\
\hline $\mathrm{p} \rightarrow \mathrm{q}$ & $\mathrm{N}$ & $\mathrm{N}$ & $\mathrm{Y}$ & $\mathrm{Y}$ & $\mathrm{Y}$ \\
\hline $\mathrm{q}$ & $\mathrm{N}$ & $\mathrm{N}$ & $\mathrm{N}$ & $\mathrm{Y}$ & $\mathrm{Y}$ \\
\hline
\end{tabular}

When this condition is met, any proposition in agenda is agreed by majority when and only when this proposition is agreed by individuals in the middle. Therefore, in this example, the majority judgment (group judgment) is judgment of 3. For the given judgment of all individuals is consistent, thus the majority judgment (group judgment) is consistent.

Then we can figure out restrictions of one-dimensional linear arrangement to judgment combinations are strong. At the same time, when the number of individuals is odd number, this restriction is effective; when the number of individuals is even number, this restriction may not fit.

\subsection{Relaxing of restriction to output}

To get rid of impossibility in judgment aggregation, we can relax restrictions to output. Impossibility theorem which we mention before asks aggregation rule of every individual judgment combination should have a corresponding consistent and complete group judgment set. Actually, it is no need for every group judgment set to be complete. And two common judgment aggregation rules which give up completeness are rule of uniformity and rule of majority.

Rule of uniformity means the group agrees with a certain agenda item, when and only when every individual agrees with this agenda item. Rule of majority is the group agrees with a certain agenda item, when and only when enough individuals such as $2 / 3,3 / 4$ agree with the agenda item. In these two situations, when a proposition and its negation do no receive the asked agreement, thus the group does not make a judgment on these agenda items.

\subsection{Weakening conditions for independence}

Weakening conditions for independence is another way to solve problems of judgment aggregation. Premise-based rules which Dietrich and Mogin have proposed in $^{[4]}$ is the most extensive discussed 
judgment aggregation rule which conditions for independence have been weakened. The basic idea here is that we first select a subset of agenda as premise set, and then we aggregate these premises through a certain judgment rule of independence. At last, we can figure out group judgment of other propositions according to group's judgment on these premises. Taking experts discussion group as example, "p: Emission load of carbon dioxide exceeds certain limit value $x$." and " $p \rightarrow q$ : If emission load of carbon dioxide exceeds certain limit value $x$, the global will get warm." and negation of these two propositions $\{\mathrm{p}, \neg \mathrm{p}, \mathrm{p} \rightarrow \mathrm{q}, \neg(\mathrm{p} \rightarrow \mathrm{q})\}$ can be taken as premises. For these premises, we can aggregate according to majority rule. And "q: The global will get warm." And its negation $\{\mathrm{q}, \neg \mathrm{q}\}$ can be taken as set of conclusion. We can decide the group judgment on conclusion through this process: the group agrees with $\mathrm{q}$, when and only when the group agrees with $\mathrm{p} \rightarrow \mathrm{q}$.

\section{Conclusion}

In the initial phase of researches on judgment aggregation, we mainly add these classical impossible conclusions on preference aggregation into judgment aggregation, and nowadays, this kind of research is more and more comprehensive.

There are at least two important researches remaining to further discussion in this field. For we introduce some specific structures which preference aggregation does not have into judgment aggregation research model, further researches on these specific structures, especially some specific structures which are under aggregation rules which have given up independence, becomes more and more important. Even though Dietrich and Mogin have made importance progress in researches based on premise-based aggregation ${ }^{[4]}$, it still remains much for us to figure out non-independence aggregation rule which has real meaning. Another important work is to expand judgment aggregation theory from binary judgment to multiple judgments. Recently years, researches on this aspect are multivalued researches of judgment aggregation and so on ${ }^{[10]}$. Compared with binary and independent judgment aggregation which has more restrictions, non-binary judgment aggregation permits more possibilities. But the difficulty is how to explicitly describe aggregation rules when the given restrictions turn to be loose.

We hope current research achievements can provide primary theory for further researches on judgment aggregation and successfully propel further researches.

\section{Acknowledgement}

This paper is one of the phased objectives of scientific research fund project "Researches on Group Rational Conditions Based on Logic of Judgment Aggregation" (GN:QD2012B003) of Mianyang Normal University and scientific project "Researches on Group Ration Aggregation from the Perspective of Modern Logic" (GN:13SB0159) of Sichuan education department.

\section{References}

1. Thomas Ågotnes, Wiebe van der Hoek, Michael Wooldridge. Towards a logic of social welfare. The 7th Conference on Logic and the Foundations of Game and Decision Theory (LOFT 06).

2. Thomas Ågotnes, Wiebe van der Hoek, Michael Wooldridge. On the logic of preference and judgment aggregation[J]. Autonomous Agents and Multi-Agent Systems (2011)22:4-30.

3. K. J. Arrow. Social Choice and Individual Values[M]. New York: Wiley, 1951; 2d edition, 1963.

4. Dietrich, F., and Mongin, P. The Premise-based Approach to Judgment Aggregation[J]. Journal of Economic Theory, 2010, 145(2):562-582.

5. Ehlers L., Storcken T. Arrow's Possibility Theorem for One Dimensional Single-peaked Preferences[J]. Games and Economic Behavior, 2008, 64(2):533-547.

6. W. Gaertner. A Primer in Social Choice Theory[M]. New York: Oxford University Press, 2009. 
7. Davide Grossi. Correspondences in the Theory of Aggregation. Lecture Notes in Computer Science, 2010, Volume 6006, Logic and the Foundations of Game and Decision Theory - LOFT 8, Pages 34-60.

8. List, C. The Theory of Judgment Aggregation: An Introductory Review. Synthese(forthcoming).

9. List, C., Puppe, C. Judgment Aggregation: A Survey. In Anand, P.,Puppe, C., Pattanaik, P.(eds.), Oxford Handbook of Rational and Social Choice, New York: Oxford University Press, 2009.

10. Pauly M., and Hees M. Logical Constraints on Judgment Aggregation[J]. Journal of Philosophical Logic, 2006, 35(6):569-585. 